\title{
Beneficial Effects of Probiotic Lactobacillus plantarum Isolated from Cow, Goat and Sheep Raw Milks
}

\section{Imen Mahmoudi*, Ameni Telmoudi and Mnasser Hassouna}

Unité de Recherche “Sciences et Technologies des Aliments", École Supérieure des Industries Alimentaires de Tunis (ESIAT), Tunis, Tunisia *Corresponding Author: Imen Mahmoudi, Unité de Recherche “Sciences et Technologies des Aliments”, École Supérieure des Industries Alimentaires de Tunis (ESIAT), Tunis, Tunisia.

Received: December 18, 2017; Published: January 11, 2018

DOI: $10.31080 /$ ASMI.2018.01.0013

\section{Abstract}

In this research, three probiotic Lactobacillus strains already studied in a previous research for their capability to resist to stomach stress, their GRAS character, their resistance to antibiotics, their prebiotic assimilation capability and their adhesion capability to intestinal human cell lines, were further investigated to explore more their beneficial effects. Compatibility between them, antibacterial activity against some pathogens, cholesterol reduction and antioxidant activity by ABTS.+ and DPPH methods were determined.

These Lactobacillus plantarum strains were compatible, able to inhibit gram+ and gram- pathogens and reduce the cholesterol with maximum level of $51 \%(\mathrm{P}<0.05)$ after $24 \mathrm{~h}$ of contact. In fact, these probiotic bacteria were endowed with important antioxidant activity while scavenging both radicals with $51 \%(\mathrm{P}<0.05)$ and $2.3 \%(\mathrm{P}>0.05)$ of ABTS.+ and DPPH respectively.

Our study revealed the suitability of these probiotic bacteria which were obtained from three sources for incorporation in foods especially where cholesterol and antioxidant reducible powers in food are sought to assess possible in vivo human health.

Keywords: Probiotic; Antibacterial Activity; Cholesterol Removal; Antioxidant Activity; Human Health

\section{Introduction}

Milk is a natural product secreted by mammals. Both food and drink, it is of great nutritional interest and lends it-self to many therapeutic, technological and industrial applications. Indeed, the importance of milk in the human diet has been well established and its regular consumption has been recommended. In addition, several studies have shown that milk represents an important source of probiotic lactic acid bacteria [1]. The study of this biological fluid could be a challenge to obtain a possible diversity of probiotic lactic acid bacteria.

Identifying and characterizing bacteria all over the world are essential in the study of human health. The term "probiotic" was defined as the active metabolites of microorganisms stimulating the growth of other microorganisms and possessing beneficial effects on host health when which consumed in sufficient quantity [2]. The acid and bile tolerance are two fundamental properties that indicate the ability of a probiotic microorganism to survive through the gastrointestinal tract.

The majority of probiotic bacteria are lactic acid bacteria, especially, such as Lactobacillus and Bifidobacterium species. In particular, Lactobacillus plantarum has the ability to grow and survive in the wide variety of foods such as meat, vegetables, milk and dairy products [3]. Furthermore, interesting features as health-promoting organisms were reported for some L. plantarum strains. Thus, this species could be used as adjunct culture in the development of new functional foods [4].
The colonization of the gut by probiotic bacteria prevents growth of many bacteria by competitive exclusion and by the production of organic acids and antimicrobial compounds. In addition, studies suggest that functional foods containing probiotics minimize the risk of heart disease and therefore, the characterization of the active ingredients and the type and number of the probiotics is important [5]. Also, antioxidant activity is an important effect of probiotics which consists in the protection of cells from oxidation problem [6]. Thus, the aim of this study was to evaluate the co-existence behaviour of probiotic strains between them, antagonistic power against pathogens, cholesterol assimilation and antioxidant properties.

\section{Materials and Methods}

Growth of probiotic strains

Three probiotic Lactobacillus plantarum strains such as BA12, CT28 and 0SO47, isolated respectively from cow, goat and sheep Tunisian raw milks, were identified and characterized in UR 13AGR 02 , ESIAT, Tunisia. The cultures were stored at $20 \%$ of glycerol at $80^{\circ} \mathrm{C}$. For this study, the probiotic cultures were activated for three times in de Mann Rogosa Sharpe (MRS) broth (Biokar Diagnostics) using $1 \%$ of inoculum and incubated at $37^{\circ} \mathrm{C}$ for $18 \mathrm{~h}$.

\section{Co-existence test}

The strains were streaked perpendicular to each other on MRS agar and incubated was done at $37^{\circ} \mathrm{C}$ for $48 \mathrm{~h}$ to observe their coexistence at the crossing points of the streaks [7]. 
Antimicrobial activity

Highlighting

The inhibitory effect of three probiotic strains was tested using the agar disc diffusion method which reported by Villani., et al [8]. For this, Salmonella typhimurium (ATCC 25922), Staphylococcus aureus (ATCC 25923), Listeria monocytogenes (ATCC 070101 121) and Escherichia coli (DH5 alpha, Institute Pasteur of Tunisia) were used as reference indicator strains.

\section{Inhibitory substance}

Staphylococcus aureus (ATCC 25923) was used as an indicator strain. The method described by Ammor., et al. [9] was used. Probiotic strains were seeded in $10 \mathrm{~mL}$ of MRS broth; after incubation at $37^{\circ} \mathrm{C}$ for $24 \mathrm{~h}$, the bacterial suspensions were centrifuged $(12,000$ rpm, 15 minutes, $4^{\circ} \mathrm{C}$ ) and the recovered supernatant was divided into 6 tubes. The contents of the first tube were neutralized to $\mathrm{pH}$ 6.5 with a solution of $\mathrm{NaOH}(1 \mathrm{~N})$ to eliminate the antagonistic effect due to the acidifying power. The contents of the second tube were neutralized and added $1.8 \mu \mathrm{L}$ of a catalase solution ( $300 \mathrm{U} / \mathrm{mL}$ ) (Sigma, France) with the aim of simultaneously eliminating the inhibitory power of organic acids and peroxide. hydrogen. The third tube was used as a control. The contents of the three tubes were used to study the antagonist activity by the well method [10]. The indicator strain was seeded in $10 \mathrm{~mL}$ of nutrient broth and incubated at $37^{\circ} \mathrm{C}$ for $24 \mathrm{~h}$. After incubation, $100 \mu \mathrm{L}$ of this culture were mixed with $20 \mathrm{~mL}$ of soft nutrient agar and poured into Petri dishes. After solidification, wells were perforated in the agar using the sterile tips. Then, each well was filled with $10 \mu \mathrm{L}$ of each of the supernatants previously prepared. If the antagonistic potency of the inhibitory activities of the neutralized supernatants was canceled, the inhibitory substance could be organic acids. If the residual antagonistic potency of the catalase-added lactic acid bacteria supernatants was zero, the inhibiting substance is hydrogen peroxide.

To study the sensitivity of the inhibitory substances to proteolytic enzymes, the supernatants of the $4^{\text {th }}$ and $5^{\text {th }}$ tubes were respectively added a solution of trypsin $(1 \mathrm{mg} / \mathrm{mL}$ ) (Sigma, France) and a solution of proteinase $\mathrm{K}(1 \mathrm{mg} / \mathrm{mL})$ (Sigma, France) each prepared in sodium phosphate buffer $(25 \mathrm{mM}, \mathrm{pH}$ 7). The supernatants were subsequently incubated respectively at $37^{\circ} \mathrm{C}$ and $45^{\circ} \mathrm{C}$ for $2 \mathrm{~h}$. The $6^{\text {th }}$ tube (control) was added only sodium phosphate buffer and incubated under the same conditions as that of the supernatant supplemented with protease. If the residual antagonistic power of the supernatants of the cultures of lactic acid bacteria incubated in the presence of proteases was reduced, it can be said that the inhibiting substance is of protein or peptide nature.

Screening of probiotic Lactobacillus strains for cholesterol removal

Cholesterol removal by probiotic Lactobacillus strains was determined 6,12 and 24h of contact according to the spectrophotometer method which previously described by Miremadi., et al. [11] and Mahmoudi., et al [12]. The ability of Lactobacillus plantarum to assimilate cholesterol was expressed as follows:

$\%$ of cholesterol removed $=(100$-residual cholesterol at each in cubation interval) $/ 100 \times 100$
Antioxidant capacity using ABTS. ${ }^{+}$method

The antioxidant capacity was determined using ABTS $^{+}(2,2$ azino-bis (3-ethylbenzothiazoline-6-sulfonic acid)) radical cation method which previously reported by Pieniz., et al. [6] and Mahmoudi., et al [12]. The percentage inhibition of ATBS.+ ${ }^{+}$was determined using ascorbic acid standard curve.

Scavenging ability on 2,2-diphenyl-1-picrylhydrazyl (DPPH) radicals

This method was already reported by Pieniz., et al. [6] and Mahmoudi., et al [12]. The results were determined using standard curve and expressed as $\mathrm{EC}_{50}(\mu \mathrm{g} / \mathrm{mL})$, which is the minimum concentration to decrease $50 \%$ of the initial DPPH reaction.

\section{Statistical analysis}

One-way ANOVA was used to investigate these tests pursued by multiple mean comparisons Student's test. The results were expressed as the mean \pm standard deviation of three repetitions. A $P$ value $<0.05$ was considered statistically significant using SPSS 20.0 .

\section{Results and Discussion}

The co-existence of the studied Lactobacillus strains is determined to ensure their compatibility in the products and therefore in the host intestine [7]. In fact, compatibility between isolated bacteria was examined by the "cross-streak" method. This method has shown that all selected bacterial strains have no antagonistic effect between them. These findings are consistent with the work of Mathieu [1] reporting that strains of Bifidobacterium and Lactobacillus, with anti-inflammatory and anti-obesity activities, were able to grow in symbiosis.

One of the main criteria of probiotic is their antagonistic capacity against certain pathogenic bacteria. In fact, they confer beneficial effects on human health by inhibiting the colonization of pathogens in the gut [13].

In this context, we tested the ability of the three probiotic Lactobacillus strains to produce antibacterial substances against pathogenic species such as Salmonella typhimurium, Staphylococcus aureus, Escherichia coli and Listeria monocytogenes. The results showed that the studied Lactobacillus probiotic bacteria were endowed with antibacterial activities on Staphylococcus aureus, Listeria monocytogenes, Salmonella typhimurium and Escherichia coli. In fact, the most important zones of inhibition were obtained on Staphylococcus aureus with a diameter of $11 \pm 0.41$ $\mathrm{mm}$ (BA12) (Table 1). The antagonistic power of these probiotic strains could be due either to their competition with the undesirable bacteria towards the nutrients, or to the production of inhibitory substances. 


\begin{tabular}{|l|c|c|c|c|c|}
\hline \multirow{2}{*}{ Probiotic strains } & \multicolumn{5}{|c|}{ Pathogen indicator strains } \\
\cline { 2 - 6 } & $\begin{array}{c}\text { Listeria } \\
\text { monocytogenes }\end{array}$ & $\begin{array}{c}\text { Salmonella } \\
\text { typhimurium }\end{array}$ & $\begin{array}{c}\text { Staphylococcus } \\
\text { aureus }\end{array}$ & $\begin{array}{c}\text { Escherichia } \\
\text { coli }\end{array}$ & Addition \\
\hline L. plantarum & & & & & \\
\hline BA12 & +++ & ++ & +++ & + & $9+$ \\
\hline CT28 & ++ & + & ++ & + & $6+$ \\
\hline OSO47 & ++ & + & ++ & + & $6+$ \\
\hline
\end{tabular}

Table 1: Antimicrobial activity data of three probiotic Lactobacillus plantarum strains against four pathogen indicator strains.

+: Presence of a clear zone of growth inhibition around spots $\leq 2 \mathrm{~mm}$;++: Presence of a clearly defined inhibition zone between

2 and $8 \mathrm{~mm}$; +++: Presence of a clearly defined inhibition zone between 8 and $12 \mathrm{~mm}$ and -: No inhibition.

The nature of the inhibitory substances released by the tested probiotic strains was studied against Staphylococcus aureus (Table 2). No antagonistic effect was detected in the bacterial supernatants adjusted to a $\mathrm{pH}$ of 6.5 and added with the catalase solution, which suggests that the antibacterial activity of these strains is not due to the production of hydrogen peroxide. Moreover, the treatment of the supernatants by proteinase $\mathrm{K}$, the protease did not inhibit their antagonistic powers, which shows that the inhibitory substance is not peptide in nature. The inhibitory activity of probiotic Lactobacillus bacteria appears to be the result of lactic acid production. Indeed, the latter can diffuse passively through the bacterial membrane in its undissociated form. It acidifies the cytoplasm after dissociation and inhibits the cellular enzymatic activity of acid-sensitive pathogens [14].

\begin{tabular}{|c|c|c|c|}
\hline \multirow{2}{*}{$\begin{array}{c}\text { Probiotic } \\
\text { strains }\end{array}$} & \multicolumn{3}{|c|}{ Inhibitor substance nature } \\
\cline { 2 - 4 } & Organic acid & $\begin{array}{c}\text { Hydrogen } \\
\text { peroxide }\end{array}$ & Bacteriocin \\
\hline L. plantarum & & & \\
\hline BA12 & + & - & - \\
\hline CT28 & + & - & - \\
\hline OSO47 & + & - & - \\
\hline
\end{tabular}

Table 2: Inhibitor substances produced by three probitic Lactobacillus plantarum strains.

+: Indicate presence; -: Indicate absence.

High blood cholesterol is generally considered to be a risk factor for cardiovascular disease. In recent years, several studies have shown that the effects of probiotic bacteria on serum cholesterol levels have a lot of remarkable beneficial interest [11]. In this context, the results relating to the reduction of cholesterol levels contained in the MRS broth, supplemented with $0.3 \%$ ox gall, by the three probiotic Lactobacillus plantarum strains are illustrated in table 3 . The ability to reduce cholesterol differs between strains by significantly different levels $(\mathrm{P}<0.05)$ even at incubation times $(6$, 12 and $24 \mathrm{~h}$ ). This assimilation varied from 19 to $51 \%$ after while $24 \mathrm{~h}$ (Table 3) of incubation compared with control.

\begin{tabular}{|c|c|c|c|}
\hline \multirow{2}{*}{$\begin{array}{c}\text { Probiotic } \\
\text { strains }\end{array}$} & \multicolumn{3}{|c|}{ Cholesterol removal (\%) } \\
\cline { 2 - 4 } & $\mathbf{6 h}$ & $\mathbf{1 2 h}$ & $\mathbf{2 4 h}$ \\
\hline L. plantarum & & & \\
\hline BA12 & $21 \pm 0.002^{\mathrm{a}}$ & $35 \pm 0.02^{\mathrm{a}}$ & $51 \pm 0.02^{\mathrm{a}}$ \\
\hline CT28 $^{\mathrm{a}}$ & $19 \pm 0.001^{\mathrm{a}}$ & $33 \pm 0.001^{\mathrm{b}}$ & $33 \pm 0.001^{\mathrm{b}}$ \\
\hline OSO47 & $20 \pm 0.004^{\mathrm{a}}$ & $34 \pm 0.08^{\mathrm{a}}$ & $49 \pm 0.001^{\mathrm{a}}$ \\
\hline
\end{tabular}

Table 3: The cholesterol removal of three probiotic Lactobacillus plantarum strains inoculated in MRS supplemented with 100 $\mu \mathrm{g} / \mathrm{mL}$ water-soluble cholesterol and $0.3 \%$ ox gall. Means are similar $(\mathrm{P}>0.05)$, they are indicated by the same letter "a".

Means are different $(\mathrm{P}<0.05)$, they are indicated by different letter "a, b".
It might be noted that this reduction is related to two factors: bacterial growth and time. Indeed, the growth of most strains tested has been improved in the presence of cholesterol, indicating that cholesterol can influence their growth [11]. It should be pointed out that the assimilation of cholesterol in the presence of ox gall showed a good correlation with the tolerance of the strains studied with bile (research papers submitted). Thus, the most important assimilation of cholesterol is obtained on $L$. acidophilus in the presence of ox gall with respect to the sodium salt and tauro-deoxycholic acid [15]. It is possible that the reduction of cholesterol by probiotic lactic acid bacteria results either by the co-precipitation of cholesterol with free bile salts. Then, a part of cholesterol was precipitated and resolubilised in the medium. Also, the assimilation of cholesterol can be done through the cells of probiotic bacteria. For it, cholesterol was presented in fragmented-cells solution. Another mechanism could be held which is the degradation of cholesterol by probiotic strains. In our research, cholesterol could not be recovered from the supernatant or washing liquid or fragmented cell solution. In fact, the partial supply of cholesterol in the probiotic cells must occur, and for that part of cholesterol can be degraded into nutritional ingredient used for the growth of probiotic strains [16]. Further research would be needed in vivo to determine the mechanism of cholesterol uptake and to determine whether or not ingestion cells of a probiotic strain could decrease the serum cholesterol levels for hypercholesterolemic humans.

On another side, The antioxidant activity of the three probiotic strains, defined as one of the beneficial effects of probiotics, was evaluated by two methods: ABTS. ${ }^{+}$and DPPH.

All supernatants of the bacterial cultures showed a high ability to trap the $\mathrm{ABTS}^{+}$radical with significant percent inhibition $(\mathrm{P}<$ 0.05 ) even at $52 \%$ compared to the control (Table 4). The strains BA12, CT28 and OSO47 showed an important antioxidant power. Probiotic bacteria have antioxidant mechanisms such as reduction of glutathione and thiol compounds, the ability to chelate metal ions, trapping reactive oxygen species and reducing activity. These protective capabilities result in antioxidant properties of certain lactobacilli bacteria and possibly provide additional food sources of antioxidants or probiotic bacteria capable of reducing oxidative stress [17].

\begin{tabular}{|c|c|c|}
\hline \multirow{2}{*}{$\begin{array}{c}\text { Probiotic } \\
\text { strains }\end{array}$} & \multicolumn{2}{|c|}{ Antioxidant activity } \\
\cline { 2 - 3 } & ABTS $^{+}(\%)$ & DPPH $\left.^{\left(E^{50}\right.}(\boldsymbol{\mu g} / \mathbf{m L})\right)$ \\
\hline L. plantarum & & \\
\hline BA12 & $51 \pm 0.001^{\mathrm{a}}$ & $2,3 \pm 0.007^{\mathrm{a}}$ \\
\hline CT28 $^{\mathrm{a}}$ & $47 \pm 0.007^{\mathrm{b}}$ & $2,6 \pm 0.002^{\mathrm{a}}$ \\
\hline OSO47 & $49 \pm 0.001^{\mathrm{a}}$ & $2,4 \pm 0.001^{\mathrm{a}}$ \\
\hline
\end{tabular}

Table 4: Antioxydant activities of three probiotic Lactobacillus strains by ABTS. ${ }^{+}$and DPPH methods.

EC50: Minimum antioxidant concentration required to reduce the initial DPPH reaction by $50 \%$.

Means are similar ( $\mathrm{P}>0.05)$, they are indicated by the same letter "a".

Means are different $(\mathrm{P}<0.05)$, they are indicated by different letter " $a, b$ ". 
In the DPPH method, we found that all strains gave varying levels of EC50 significantly lower than that given by the control (Table 4)

These observations are consistent with those found by the previous method. Similarly, Meira., et al. [18] and Pieniz., et al. [6] reported that L. plantarum, L. casei and Enterococcus durans strains, isolated from cheese, are also endowed with important antioxidant activities. It should be noted that our strains have strong antioxidant potentials and can be used to reduce oxidative phenomena in food products. Nevertheless, using intact cells as passing delivery vehicles Through the gastrointestinal tract, intracellular constituents released by lactic acid bacteria in the gastro-intestinal tract can also be antioxidants [6]. Consumption of foods containing probiotic lactic acid bacteria may be recommended as sanitary. Indeed, it is well established that a wide variety of oxygen free radicals are produced continuously in food and in the human body [19]. In addition to the long history of consumption, which proves the beneficial effects of probiotic lactic acid bacteria, it has been noted that these microorganisms are desirable for a recommended use in the production of various functional foods with benefits to human health.

\section{Conclusion}

Finally, being highly resistant to environmental stress and to simulate severe conditions prevailing in the gastro-intestinal tract and, on the other hand, having important anti-bacterial, hypocholesterolimiant and anti-oxidative properties, the Lactobacillus plantarum strains BA12, CT28 and OSO47 constitute three potential candidates that may be involved in the formulation of functional food categories.

\section{Bibliography}

1. Mathieu VD. "Viabilité, propriétés technologiques et effets anti-inflammatoires et anti-obésité de nouvelles souches probiotiques dans les produits laitiers". Thèse de doctorat. Université Quebec. Canada (2015).

2. Haghshenas B., et al. "Anticancer impacts of potentially probiotic acetic acid bacteria isolated from traditional dairy microbiota". LWT Food Science and Technology 60.2 (2015): 690-697.

3. Corsetti A., et al. "Lactobacillus spp.: Lactobacillus plantarum". In JW Fuquay, PF Fox, and PLH McSweeney (Eds.), Encyclopedia of dairy science (2 ${ }^{\text {nd }}$ edition). New York, NY, USA: Elsevier Science Academic Press Volume 3 (2011): 111-118.

4. Zago M., et al. "Characterization and probiotic potential of Lactobacillus plantarum strains isolated from cheeses". Food Microbiology 28.5 (2011): 1033-1040.

5. Shahidi F. "Nutraceuticals, functional foods and dietary supplements in health and disease". Journal of Food and Drug Analysis 20.1 (2012): 226-230.

6. Pieniz S., et al. "Probiotic potential, antimicrobial and antioxidant activities of Enterococcus durans strain LAB18s". Food Control 37 (2014): 251-256.

7. Guo CF., et al. "Screening for cholesterol-lowering probiotic based on deoxycholic acid removal pathway and studying its functional mechanisms in vitro". Anaerobe 18.5 (2012): 516522 .
8. Villani F., et al. "Partial characterization of an antagonistic substance produced by Staphylococcus xylosus $1 \mathrm{E}$ and determination of the effectiveness of the producer strain to inhibit Listeria monocytogenes in Italian sausage". Journal of Food Microbiology 14.6 (1997): 555-566.

9. Ammor S., et al. "Antibacterial activity of lactic acid bacteria against spoilage and pathogenic bacteria isolated from the same meat small-scale facility - Screening and characterisation of antibacterial compounds". Food Control 22 (2005): 529-538.

10. Papamaloni E., et al. "Characterization of Micrococcaceae isolated from dry fermented sausage". Journal of Food Microbiology 19.5 (2002): 441-449.

11. Miremadi F., et al. "Cholesterol reduction mechanisms and fatty acid composition of cellular membranes of probiotic Lactobacilli and Bifidobacteria”. Journal of Functional Foods 9 (2014): 295-305.

12. Mahmoudi I., et al. "Symbiotic, Hypocholesterolemic and Antioxidant Effects of Potential Probiotic Lactobacilli Strains Isolated from Tunisian Camel Milk". Advances in Microbiology 7.4 (2017): 328-342.

13. Garcia Fontan M., et al. "Microbiological characteristics of "androlla", a Spanish traditional pork sausage". Food Microbiology 24.1 (2007): 52-58.

14. Servin AL. "Antagonistic activities of lactobacilli and bifidobacteria against microbial pathogens". FEMS Microbiology Reviews 28.4 (2004): 405-440.

15. Lye HS., et al. "Removal of cholesterol by lactobacilli via incorporation and conversion to coprostanol". Journal of Dairy Science 93.4 (2010): 1383-1392.

16. Guo LD., et al. "Cholesterol Removal by Lactobacillus plantarum Isolated from Homemade Fermented Cream in Inner Mongolia of China". Czech Journal of Food Sciences 29.3 (2011): 219-225.

17. Wang YP., et al. "Effects of Lactobacillus plantarum MA2 isolated from Tibet kefir on lipid metabolism and intestinal microflora of rats fed on high-cholesterol diet". Applied in Microbiology and Biotechnology 84.2 (2009): 341-347.

18. Meira SMM., et al. "Probiotic potential of Lactobacillus spp. isolated from Brazilian regional ovine cheese". Journal of Dairy Research 79.1 (2012): 119-127.

19. Lobo V., et al. "Free radicals, antioxidants and functional foods: impact on human health". Pharmacognosy Review 4.8 (2010): 118-126.

Volume 1 Issue 2 February 2018 (C) All rights are reserved by Imen Mahmoudi., et al. 